\title{
Interstitial Photodynamic Therapy Using 5-ALA for Malignant Glioma Recurrences
}

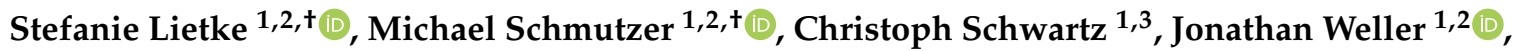 \\ Sebastian Siller ${ }^{1,2}{ }^{\oplus}$, Maximilian Aumiller ${ }^{4,5}{ }^{\oplus}$, Christian Heckl ${ }^{4,5}{ }^{-}$, Robert Forbrig ${ }^{6}$, Maximilian Niyazi ${ }^{2,7}$, \\ Rupert Egensperger ${ }^{8}$, Herbert Stepp ${ }^{4,5}{ }^{\circ}$, Ronald Sroka ${ }^{4,5}{ }^{\circ}$, Jörg-Christian Tonn ${ }^{1,2}$, Adrian Rühm ${ }^{4,5, \ddagger}$ and \\ Niklas Thon $1,2, *, \ddagger$
}

check for updates

Citation: Lietke, S.; Schmutzer, M.; Schwartz, C.; Weller, J.; Siller, S.; Aumiller, M.; Heckl, C.; Forbrig, R.; Niyazi, M.; Egensperger, R.; et al. Interstitial Photodynamic Therapy Using 5-ALA for Malignant Glioma Recurrences. Cancers 2021, 13, 1767. https://doi.org/10.3390/cancers 13081767

Academic Editors: Giuseppe Lombardi, Emilie Le Rhun, Ahmed Idbaih, Matthias Preusser and Pim French

Received: 23 February 2021

Accepted: 29 March 2021

Published: 7 April 2021

Publisher's Note: MDPI stays neutral with regard to jurisdictional claims in published maps and institutional affiliations.

Copyright: (c) 2021 by the authors. Licensee MDPI, Basel, Switzerland. This article is an open access article distributed under the terms and conditions of the Creative Commons Attribution (CC BY) license (https:/ / creativecommons.org/licenses/by/ $4.0 /)$.
1 Department of Neurosurgery, University Hospital, LMU Munich, 81377 Munich, Germany

2 German Cancer Consortium (DKTK), Partner Site Munich, 81377 Munich, Germany

3 Department of Neurosurgery, University Hospital Salzburg, Paracelsus Medical University Salzburg, 5020 Salzburg, Austria

4 Laser-Forschungslabor, LIFE Center, University Hospital, LMU Munich, 81377 Munich, Germany

5 Department of Urology, University Hospital, LMU Munich, 81377 Munich, Germany

6 Institute for Clinical Neuroradiology, University Hospital, LMU Munich, 81377 Munich, Germany

Department of Radiation Oncology, University Hospital, LMU Munich, 81377 Munich, Germany

8 Center for Neuropathology and Prion Research, University Hospital, LMU Munich, 81377 Munich, Germany

* Correspondence: niklas.thon@med.uni-muenchen.de; Tel.: +49-89-4400-0

$+\quad$ Both authors contributed equally.

$\ddagger \quad$ This study is guided by AR and NT equally thus both serve as shared last authors.

Simple Summary: Malignant glioma has a poor prognosis, especially in recurrent situations. Interstitial photodynamic therapy (iPDT) uses light delivered by implanted light-diffusing fibers to activate a photosensitizing agent to induce tumor cell death. This study examined iPDT for the treatment of malignant glioma recurrences. Forty-four patients treated at one institution were retrospectively analyzed and patient-, tumor- and treatment-related factors were retrieved from hospital charts. Most of the patients (37) had glioblastomas, the most aggressive type of glioma. Brain swelling or small bleedings caused worsening of symptoms in 18 patients, but only in one case severe symptoms persisted for more than six weeks. After iPDT, tumors recurred after a median of 7.1 months and patients lived for a median of 13.0 months. Two years after iPDT treatment, $25 \%$ of the patients were still alive. These promising results should be evaluated further in a prospective study.

Abstract: Interstitial photodynamic therapy (iPDT) using 5-aminolevulinic acid (5-ALA)-induced protoporphyrin IX (PpIX) as a cytotoxic photosensitizer could be a feasible treatment option for malignant gliomas. In a monocentric cohort of consecutive patients treated between 2006 and 2018, a risk profile analysis of salvage iPDT for local malignant glioma recurrences and associated outcome measures are presented here. It was considered indicated in patients with circumscribed biopsy-proven malignant glioma recurrences after standard therapy, if not deemed eligible for safe complete resection. A 3D treatment-planning software was used to determine the number and suitable positions of the cylindrical diffusing fibers placed stereotactically to ensure optimal interstitial irradiation of the target volume. Outcome measurements included the risk profile of the procedure, estimated time-to-treatment-failure (TTF), post-recurrence survival (PRS) and prognostic factors. Forty-seven patients were treated, of which 44 (median age, 49.4 years, range, 33.4-87.0 years, 27 males) could be retrospectively evaluated. Recurrent gliomas included 37 glioblastomas (WHO grade IV) and 7 anaplastic astrocytomas (WHO grade III). Thirty (68.2\%) tumors were O-6methylguanine-DNA methyltransferase (MGMT)-methylated, 29 (65.9\%)-isocitrate dehydrogenase (IDH)-wildtype. Twenty-six (59.1\%) patients were treated for their first, 9 (20.5\%)—for their second, 9 $(20.5 \%)$ - for the third or further recurrence. The median iPDT target volume was $3.34 \mathrm{~cm}^{3}$ (range, $0.50-22.8 \mathrm{~cm}^{3}$ ). Severe neurologic deterioration lasted for more than six weeks in one patient only. The median TTF was 7.1 (95\% confidence interval (CI), 4.4-9.8) months and the median PRS was 13.0 (95\% CI, 9.2-16.8) months. The 2- and 5-year PRS rates were $25.0 \%$ and $4.5 \%$, respectively. The treatment response was heterogeneous and not significantly associated with patient characteristics, 
treatment-related factors or molecular markers. The promising outcome and acceptable risk profile deserve further prospective evaluation particularly to identify mechanisms and prognostic factors of favorable treatment response.

Keywords: malignant glioma; glioblastoma; recurrence; photodynamic therapy; 5-ALA; stereotactic surgery; outcome

\section{Introduction}

Despite recent advances in the treatment of malignant glioma, prognosis remains poor with a median overall survival (OS) of less than two years in IDH-wildtype glioblastomas $[1,2]$. Upon inevitable tumor recurrence, median post-recurrence survival (PRS) is limited to 7-12 months in most recent studies [3-12]. Salvage treatment options include resurgery, reirradiation protocols, chemotherapy and any combination thereof. Each of these treatment options offers specific advantages and limitations. While salvage surgery can be of advantage in selected cases, only complete resection of the contrast-enhancing tumor mass seems to prolong post-recurrence survival [10,13-15]. In the case of eloquent, diffuse and/or multifocal tumor recurrences, reirradiation and/or second-line chemotherapy regimens may be preferable $[16,17]$. No randomized controlled study, however, has been able to show a relevant survival benefit for any of the treatment regimens tested [18-25]. This also concerns the use of recently introduced tumor-treating fields [6] and some early results from immunotherapy [26]. Accordingly, no standard treatment for progressive/recurrent malignant gliomas exists, and therefore, management has to be optimally tailored to the individual patient [27].

Photodynamic therapy (PDT) has been introduced as a local surgical treatment option which is based on cytotoxic effects induced by a photosensitizing agent that is accumulated within malignant glioma tissue and activated by light of an appropriate wavelength [28]. PDT for malignant glioma was developed alongside fluorescence-guided resection with 5-aminolevulinic acid (5-ALA) [29] which provides highly tumor-specific fluorescence in combination with minimal side effects: in an approval study [29] as well as in a more recent assessment [30], safety concerns with respect to drug application or morbidity caused by fluorescence-guided resection did not exceed the ones of standard surgery. PDT can be applied as surface PDT within a resection cavity [31-33]. At our institution, PDT is applied as interstitial PDT (iPDT) by cylindrical diffusing fibers that are stereotactically inserted to ensure a spatially precise interstitial irradiation of the target tumor volume. In a former iPDT series of 10 patients with local recurrence of a malignant glioma after multimodal therapy, we demonstrated the feasibility and tolerability of iPDT [28]. In addition, cases of remarkably long tumor control have been observed [34]. Here, results of salvage iPDT of patients $(N=44)$ suffering from local malignant glioma recurrences after standard therapy are presented. Special attention is given to the risk profile of iPDT and associated outcome parameters in this selected patient cohort.

\section{Patients and Methods}

\subsection{Patient Selection}

At our institution, salvage iPDT was considered in adult patients with a Karnofsky performance score (KPS) of at least 70 who presented with a unifocal circumscribed malignant glioma recurrence after standard multimodal therapy. Local tumor recurrence or progressive disease as suspected by contemporary measurements $[35,36]$ must not exceed a maximum extension of $3 \mathrm{~cm}$ defined by the contrast-enhancing tumor volume in gadolinium T1-weighted magnetic resonance imaging (MRI). As part of clinical routine, viable tumor tissue was always histologically verified upfront by minimally invasive stereotactic biopsy procedures [37] to exclude treatment-associated effects or pseudoprogression. Use of iPDT was considered indicated in consensus by the neurooncological tumor board when 
other local therapy options such as (re-)resection or (re-)radiotherapy alone were deemed not to be safely feasible or refused by the patient who qualified for novel experimental treatment options.

For this single-center retrospective analysis, all 47 consecutive patients who underwent salvage iPDT for malignant glioma recurrences between 2006 and 2018 were included. In three patients, however, no follow-up data were availableAll patients provided written informed consent to treatment. This retrospective investigation was approved by the ethics committee of the Ludwig Maximilian University, Munich, Germany (reference number 19-650).

\subsection{Magnetic Resonance Imaging Protocol}

Magnetic resonance imaging always included three-dimensional gadolinium-enhanced T1- (1 mm slices) and T2-weighted ( $2 \mathrm{~mm}$ slices) scans preoperatively and thereafter. Early postoperative MRI was routinely performed within $48 \mathrm{~h}$ after iPDT treatment and additionally included diffusion-weighted imaging (DWI) and apparent diffusion coefficient (ADC) to assess early treatment effects.

\subsection{Neuropathological Analysis}

Neuropathological diagnosis of tumor recurrence was performed according to the respective valid WHO classification from the years 2007 and 2016 [38,39]. After 2009, pyrosequencing was performed routinely to determine isocitrate dehydrogenase (IDH) mutational status and microsatellite analysis for $1 \mathrm{p} / 19 \mathrm{q}$ codeletion status. In all patients for whom materials were available, IDH mutations were analyzed retrospectively. O-6methylguanine-DNA methyltransferase (MGMT) promoter methylation was analyzed by methylation-specific PCR and sequencing.

\subsection{Interstitial PDT Protocol}

Interstitial illumination was performed using a diode laser (Ceralas Diode Laser, Biolitec AG, Jena, Germany) and cylindrical diffusing fibers as described before [25]. The target volume was defined after multimodal image fusion of the intraoperative stereotactic CT (contrast-enhanced scans, $0.6 \mathrm{~mm}$ axial slices) with the preoperative MRI and, if available, O-(2-[ $\left.{ }^{18} \mathrm{~F}\right]$ fluoroethyl)-L-tyrosine (18F-FET)-PET scan. A spatially precise interstitial irradiation of the individual tumor volumes was planned using the @target 1.19 software (Brainlab, Munich, Germany) [29].

The patients were administered $20 \mathrm{mg} / \mathrm{kg}$ body weight of 5-ALA three to five hours before the start of iPDT illumination. Depending on tumor geometry, cylindrical diffusing fibers with an active diffuser length of, optionally, $20 \mathrm{~mm}$ or $30 \mathrm{~mm}$ were selected. The fibers had an outer diameter of $1600 \mu \mathrm{m}$ (CeramOptec GmbH, Bonn, Germany) (first 26 treatments) and $1560 \mu \mathrm{m}$ (Light Guide Optics, Rheinbach, Germany) (last 18 treatments), respectively. The fibers were stereotactically inserted with 6 to $12 \mathrm{~mm}$ interfiber distances using a modified Riechert stereotactic frame system (Medical High Tech GmbH, BadKrozingen-Biengen, Germany). Prior to fiber placement, a mandrin was inserted into the brain along the trajectory to the target to prepare a channel for the fibers and to serve as a reference for an accurate implantation procedure by means of an orthogonal C-arm X-ray evaluation (Siemens Healthineers, Erlangen, Germany). Correct positioning of the light diffusers within the target volume was then ensured using metallic X-ray markers integrated at the distal and proximal ends of the active segment of the cylindrical diffusing fibers. During therapy, patients received mechanical ventilation with $100 \%$ oxygen to ensure adequate oxygen supply for the production of free radicals. Interstitial PDT irradiation was performed with a laser light of $635 \mathrm{~nm}$ wavelength at the illumination power of $200 \mathrm{~mW} / \mathrm{cm}$ diffuser length for a treatment time of $60 \mathrm{~min}$. In cases where the treatment plan resulted in small interfiber distances, the illumination power was decreased and the illumination time was prolonged. Illumination was stopped after the scheduled time if no residual fluorescence was observed. Intraoperative spectral online monitoring 
was performed prior to and after iPDT illumination as described previously $[33,40]$. In brief, one after the other, each cylindrical diffusing fiber was used as an emitter, while each of the other fibers sequentially served as an optical detection probe connected to a spectrometer (S2000 or USB2000+, Ocean Optics/Ocean Insight, Ostfildern, Germany) measuring the detected light in the wavelength range of $550 \mathrm{~nm}$ to $800 \mathrm{~nm}$. After iPDT irradiation, the cylindrical diffusing fibers were removed.

\subsection{Spectral Online Monitoring Analysis}

The acquired spectral online monitoring data were analyzed for detectable transmitted treatment light at $635 \pm 3 \mathrm{~nm}$ and protoporphyrin IX (PpIX) fluorescence signals at $705 \pm 3 \mathrm{~nm}$. To distinguish between signal artifacts and the true signal, a signal threshold of three times the signal-to-noise ratio was assumed. In addition, only fiber pairs less than $19 \mathrm{~mm}$ apart were used for spectral analyses. If at least $75 \%$ of all transmission or fluorescence signals of a patient showed a true signal, the patient was graded as good, otherwise-as poor.

\subsection{Perioperative Management and Risk Assessment of iPDT}

All iPDT procedures were performed under general anesthesia. In order not to inhibit antitumor immunological effects, no cortisone was administered peri- and postoperatively except in case of uncontrolled edema causing severe neurological deterioration.

Any perioperative sequelae resolving within six weeks were considered transient, all others-as permanent complications of this kind of iPDT treatment. Severity was classified according to the Common Terminology Criteria for Adverse Events Version 5 (CTCAE) [41].

\subsection{Treatment after iPDT and Follow-Up Evaluation}

The decision to perform iPDT as standalone treatment or in combination with additional salvage treatment was made individually by the interdisciplinary neurooncological tumor board considering each patient's risk profile, previous therapies, as well as molecular tumor characteristics.

Patients were followed in the outpatient clinic for six weeks after therapy and in threemonth intervals thereafter. Radiologic tumor recurrence was defined according to MacDonald or after the response assessment in neuro-oncology (RANO) 2010 criteria [35,36]. Once validated FET-PET data had become available [42,43], FET-PET examination was used, partially in combination with rebiopsy, to rule out pseudoprogression in unclear non-palliative cases.

\subsection{Statistical Evaluation}

The reference point for overall survival (OS) was the date of the initial tumor diagnosis. Time-to-treatment failure (TTF) and post-recurrence survival (PRS) were calculated from the date of iPDT. Patients had been followed until the last patient died. The distribution of continuous (categorical) variables was analyzed by means of the Wilcoxon test $\left(X^{2}\right.$ statistics). Survival was analyzed with the Kaplan-Meier method. A Cox proportional hazards model was used to identify epidemiologic and molecular prognostic factors. Differences between responders and non-responders were analyzed using logistic regression models. The complete statistical analysis was performed with the use of SPSS Statistics 25 (IBM, Armonk, New York, USA). The significance level was set to $p \leq 0.05$.

\section{Results}

\subsection{Patient Characteristics}

This study included 44 patients (27 (61.4\%) males) (Table 1) between 2006 and 2018. The median age at the time of iPDT was 49.4 years (range, 33.4-87.0 years) and the median KPS was 90 (range, 70-100) (Table 1). The median time between initial tumor diagnosis and salvage iPDT was 16.9 months (range, 3.5-192.4 months). Twenty-six (59.1\%) patients were treated for their first, $9(20.5 \%)$ - for their second, $9(20.5 \%)$-for the third or 
further recurrence. Thirty-six (81.8\%) patients had undergone open tumor resection, 43 $(97.7 \%)$ patients had been treated with percutaneous irradiation and $39(88.6 \%)$-with chemotherapy before salvage iPDT for circumscrbed tumor recurrences was considered. At the time of salvage iPDT, $37(84.1 \%)$ of the recurrent tumors were classified as WHO grade IV glioblastomas, 7 (15.9\%) —as WHO grade III anaplastic astrocytomas. Six (13.6\%) patients suffered from a malignant transformation of an initially diagnosed WHO grade II diffuse astrocytoma. Twenty-nine (65.9\%) of the tumors were IDH-wildtype tumors, 9 $(20.5 \%)$ had an IDH mutation. For six patients, residual tumor material was insufficient for retrospective analysis of the IDH status. A methylated MGMT promoter status was recorded for $30(68.2 \%)$ tumors as part of the integrated histopathological diagnosis.

Table 1. Summary of patients' characteristics.

\begin{tabular}{|c|c|}
\hline Characteristics at iPDT & All Patients $(N=44)$ \\
\hline \multicolumn{2}{|l|}{ Age (years) } \\
\hline Median & 49.4 \\
\hline Range & $33.4-87.0$ \\
\hline \multicolumn{2}{|l|}{ Gender, n (\%) } \\
\hline Male & $27(61.4)$ \\
\hline Female & $17(38.6)$ \\
\hline \multicolumn{2}{|l|}{ KPS, n (\%) } \\
\hline 100 & $3(6.8)$ \\
\hline 90 & $29(65.9)$ \\
\hline 80 & $9(20.5)$ \\
\hline 70 & $3(6.8)$ \\
\hline \multicolumn{2}{|l|}{ Symptoms, n (\%) } \\
\hline Seizures & $27(61.4)$ \\
\hline Aphasia without paresis & $12(27.3)$ \\
\hline Paresis without aphasia & $4(9.1)$ \\
\hline Aphasia and paresis & $1(2.3)^{1}$ \\
\hline \multicolumn{2}{|l|}{ Side, $\mathrm{n}(\%)$} \\
\hline Right & $20(45.5)$ \\
\hline Left & $24(54.5)$ \\
\hline \multicolumn{2}{|l|}{ Localization, n (\%) } \\
\hline Deep-seated involvement & $31(70.5)$ \\
\hline Eloquent lobar localization & $17(38.6)$ \\
\hline \multicolumn{2}{|l|}{ Stage of disease, $\mathrm{n}(\%)$} \\
\hline First tumor recurrence & $26(59.1)$ \\
\hline Second tumor recurrence & $9(20.5)$ \\
\hline Third tumor recurrence & $6(13.6)$ \\
\hline Later stages & $3(6.8)$ \\
\hline \multicolumn{2}{|l|}{ WHO grade, $\mathrm{n}(\%)$} \\
\hline IV & $37(84.1)$ \\
\hline III & $7(15.9)$ \\
\hline
\end{tabular}


Table 1. Cont.

\begin{tabular}{cc}
\hline Characteristics at iPDT & All Patients $(\mathbf{N}=\mathbf{4 4})$ \\
\hline WHO grade at initial diagnosis, $\mathrm{n}(\%)$ & \\
IV & $30(68.2)$ \\
III & $8(18.2)$ \\
II & $6(13.6)$ \\
MGMT promoter methylation status, n (\%) & $30(68.2)$ \\
Methylated & $14(31.8)$ \\
Unmethylated & \\
IDH mutation, $\mathrm{n}(\%)$ & $29(65.9)$ \\
Wildtype & $9(20.5)$ \\
Mutated & $6(13.6)$ \\
Unknown (no material left) & $1(2.3)$ \\
1 p/19 q codeletion, $\mathrm{n}(\%)$ & $20(45.5)$ \\
1 p/19 q codeletion & $23(52.3)$ \\
No 1 p $/ 19$ q codeletion & \\
Not tested &
\end{tabular}

${ }^{1}$ Percentages may not total 100.0 due to rounding.

\subsection{Interstitial PDT Treatment}

The median iPDT target volume was $3.34 \mathrm{~cm}^{3}$ (range, $0.50-22.8 \mathrm{~cm}^{3}$ ), targeted with a median of 4 (range, 3-8) cylindrical diffusing fibers (Table 2). The minimum irradiation time of $60 \mathrm{~min}$ (range, 60-167 $\mathrm{min}$ ) was received by 29 patients. The median applied light power per $\mathrm{cm}$ diffusor length was $200 \mathrm{~mW}$ (range, $82-210 \mathrm{~mW}$ ). The median energy dose applied during iPDT illumination was $8996 \mathrm{~J}$ (range, 5760-17,388 J), largely depending on the iPDT target volume and the corresponding adapted number of cylindrical diffusing fibers.

Table 2. Treatment characteristics.

\begin{tabular}{cc}
\hline Treatment Algorithms & All Patients $(\mathbf{N}=\mathbf{4 4})$ \\
\hline Treatment before iPDT, $\mathbf{n}(\mathbf{\%})$ & $36(81.9)$ \\
Tumor resection & $43(97.7)$ \\
Irradiation & $39(88.6)$ \\
Chemotherapy & \\
Interstitial PDT characteristics & \\
Target volume $\left(\mathrm{cm}^{3}\right)$ & 3.34 \\
Median & $0.50-22.8$ \\
$\quad$ Range & $4(3-8)$ \\
Number of cylindrical diffusing fibers (range) & \\
Applied light power per diffuser length & \\
(mW/cm) & 200 \\
Median & $82-210$ \\
Range & \\
Treatment dose (J) & 8883 \\
Median & $5760-17,388$ \\
Range & $60(N=29)$ \\
Median & $60-167$ \\
Range & \\
Treatment time (minutes) & $20(45.4)$ \\
Chemotherapy & $7(15.9)$ \\
Radiotherapy & $4(9.1)$ \\
Radiochemotherapy & \\
Any chemotherapy & $31(70.5)$ \\
Any (re-)radiotherapy & $20(45.5)$ \\
Any tumor resection/debulking & $4(9.1)$ \\
\hline
\end{tabular}




\subsection{Imging after iPDT}

Early postoperative imaging within $48 \mathrm{~h}$ after iPDT showed a decrease or effacement of contrast enhancement in all cases. Typically, diffusion restriction occurred in the treated area (Figure 1). A transient increase in edema surrounding the tumor treatment volume was seen in 12 cases, six of which caused transient neurological deterioration (two-paresis, four-aphasia).

T1 with contrast

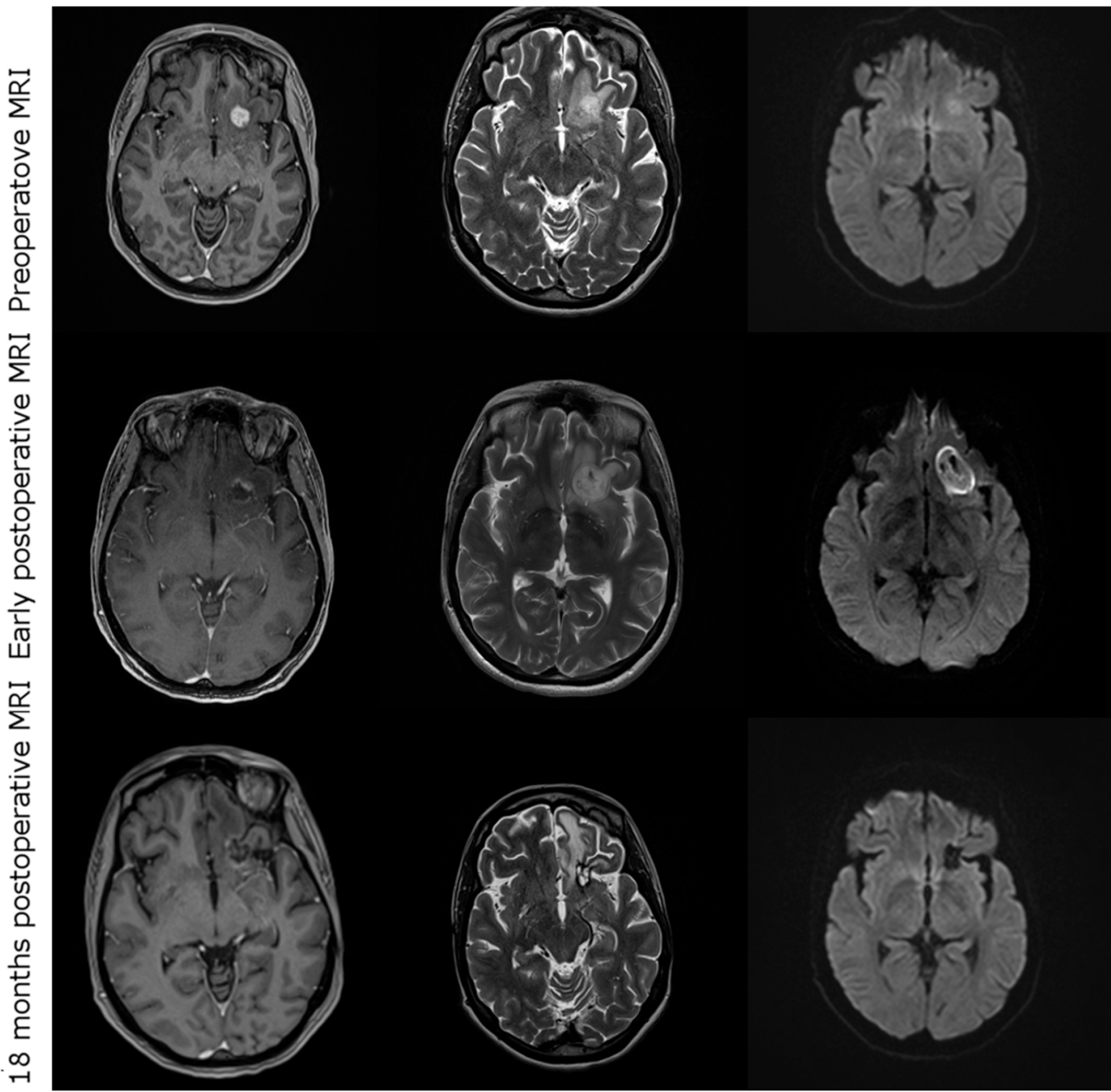

Figure 1. Exemplary case of a 41-year-old female patient suffering from a left frontal glioblastoma recurrence causing mild aphasia. Post-iPDT MRI showing characteristic changes such as disappearance of contrast enhancement, diffusion restriction within the treatment volume and mild perifocal edema. Peri-interventionally, there was transient worsening of aphasia, which then resolved completely in subsequent weeks.

\subsection{Complications after iPDT}

Complications after iPDT are listed in Table 3. Overall, 18 patients (40.0\%) experienced transient worsening of the usually preexistent neurological deficits, i.e., mainly incomplete aphasia and/or hemiparesis. One patient developed malignant edema and underwent emergency decompression within $24 \mathrm{~h}$ after iPDT treatment. In this case, only slight word-finding difficulties ( $\left.\mathrm{CTCAE}^{\circ} 2\right)$ persisted. After six weeks, most deficits resolved or would not inhibit activities of daily life $\left(N=9, \mathrm{CTCAE}^{\circ} 1\right)$. Three patients $(6.8 \%)$ suffered from residual deficits; in one case, self-care was affected (CTCAE $\left.{ }^{\circ} 3\right)$. Postoperative complications were not found to correlate with the patients' TTF $(p=0.841)$ and PRS $(p=0.492)$. 
Table 3. Complications after iPDT.

\begin{tabular}{cc}
\hline Complications after iPDT & All Patients $(\boldsymbol{N}=\mathbf{4 4})$ \\
\hline Postoperative CTCAE grade, $N(\%)$ & $26(59.1)$ \\
0 & $4(9.1)$ \\
1 & $10(22.7)$ \\
2 & $3(6.8)$ \\
4 & $1(2.3)$ \\
5 & $0(0.0)$ \\
CTCAE grade at six weeks, $N(\%)$ & \\
0 & $32(72.7)$ \\
1 & $9(20.5)$ \\
2 & $2(4.5)$ \\
4 & $1(2.3)$ \\
5 & $0(0.0)$ \\
Type of complications, $N(\%)$ & $0(0.0)$ \\
Aphasia & $7(15.9)$ \\
Paresis & $6(13.6)$ \\
Paresis and aphasia & $4(9.1)$ \\
Hyp-/dysaesthesia only & $1(2.3)$ \\
None & $26(59.1)$ \\
\hline
\end{tabular}

The bold cells are sub-headlines.

\subsection{Treatment after iPDT}

As part of a predefined combined treatment algorithm, iPDT was immediately followed by chemotherapy in 20 cases (45.5\%; temozolomide, $N=14,31.8 \%$; procarbazine/ lomustine, $N=6,13.6 \%)$ and by re-radiotherapy with/without chemotherapy in $11(25.0 \%)$ cases (Table 2). At the time of tumor progression after iPDT treatment, all patients were found eligible for additional multimodal treatment (31 (70.5\%) patients were treated with chemotherapy, $20(45.5 \%)$ received re-radiotherapy and $4(9.1 \%)$ underwent open tumor debulking for space-occupying recurrences before salvage chemotherapy was initiated). No immediately palliative case (usually confined to best supportive care only) was observed. Patients with MGMT-methylated tumors did not receive more or less often radiotherapy $(p=0.81)$ or chemotherapy $(p=0.92)$ in the further course of their disease.

\subsection{Outcome}

The median follow-up duration was 13.0 months (range, 4.7-105.6 months). In three patients, however, no follow-up data were available. Within their individual follow-up duration, all the remaining patients experienced tumor progression and died, with all recorded deaths being tumor-related. Here, the median OS from the first tumor diagnosis was 39.7 months (range, 9.8-199.0 months). The median time between the first diagnosis and salvage iPDT was 16.9 months (range, 3.5-192.4 months), median TTF after iPDT was 7.1 months (range, $0.6-93.9$ months; $95 \%$ confidence interval (CI), 4.4-9.8) and median PRS was 13.0 months (range, 4.7-105.6 months; CI, 9.2-16.8) (Figure 2). When the three patients lost to follow-up were also included in the analysis (as part of the intended-to-treat population), median TTF was 6.8 months and mean PRS was 12.5 months (Supplementary Figure S1). As can be derived from Figure 2, six- and twelve-months recurrence-free survival rates after salvage iPDT were $59.1 \%$ and $34.1 \%$, respectively. Six- and twelvemonths survival rates after iPDT were $88.6 \%$ and $63.6 \%$, respectively. Two years after iPDT treatment, eleven $(25.0 \%)$ patients were alive, seven $(15.9 \%)$ of them recurrence-free. 


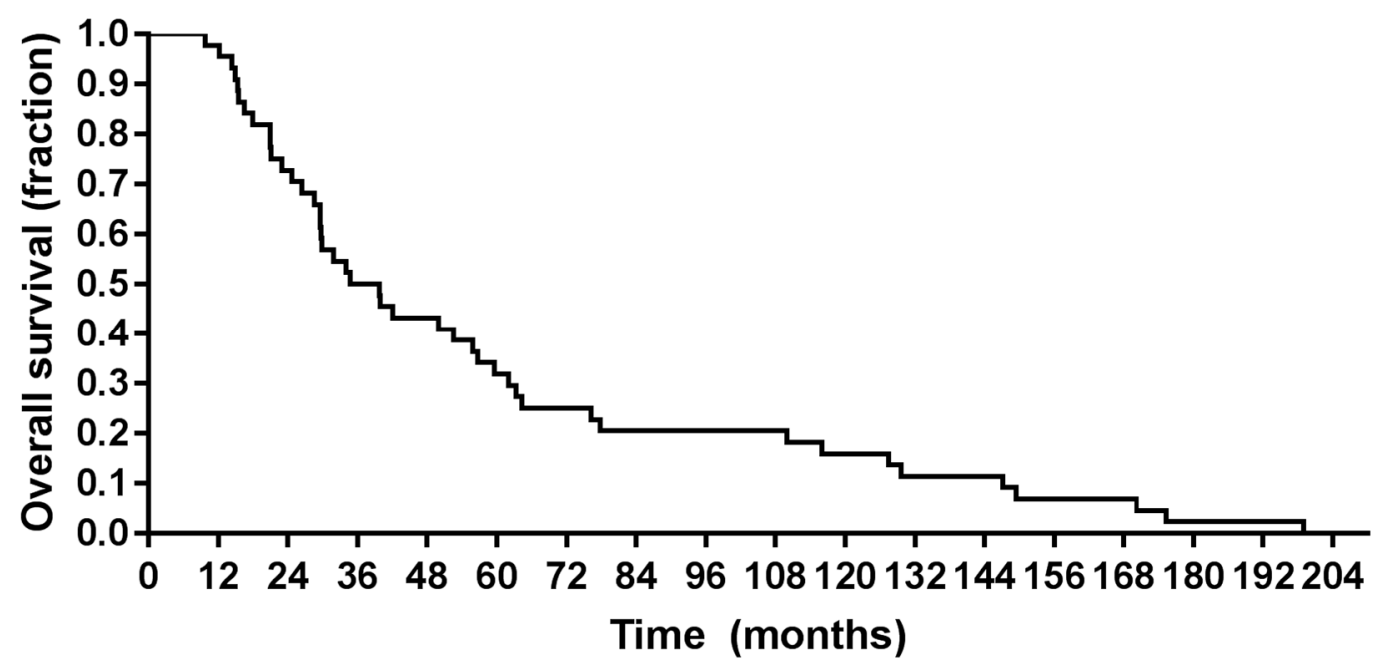

(a)

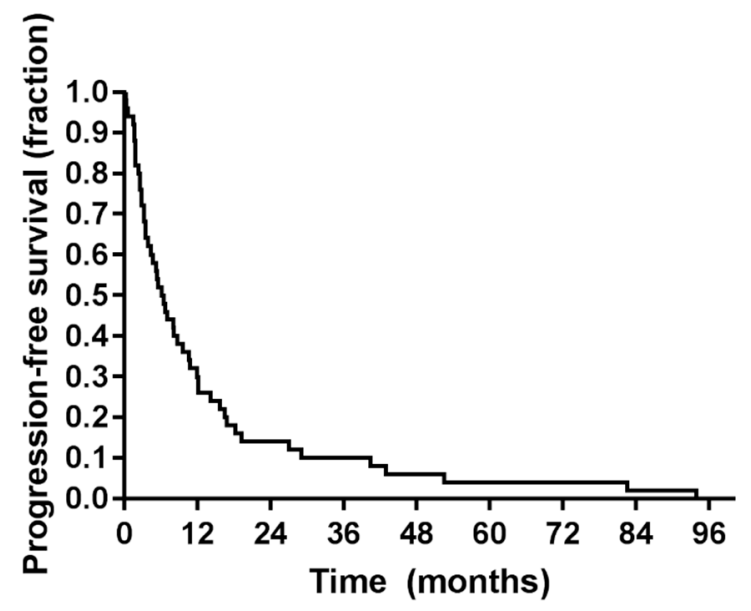

(b)

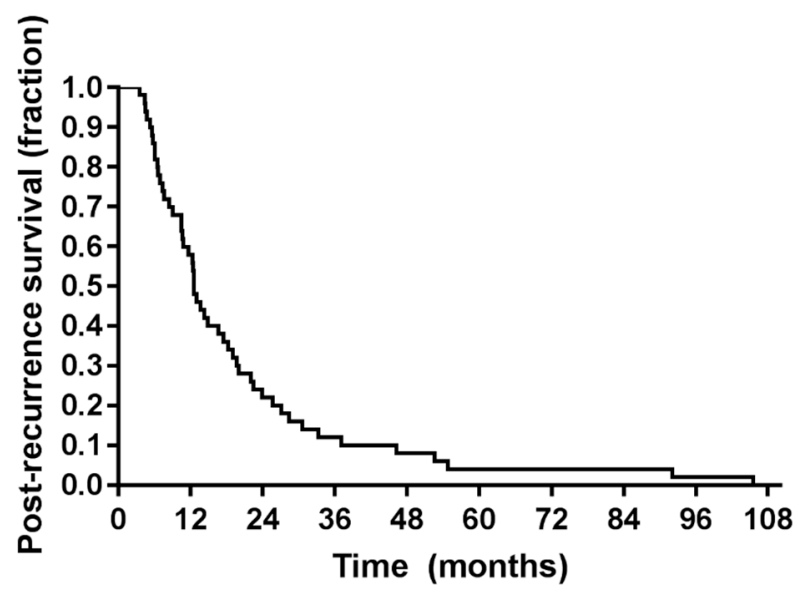

(c)

Figure 2. Survival curves. (a) Overall survival of the study population after initial tumor diagnosis; (b) time-to-treatment failure (TTF) of the study population after iPDT treatment; (c) post-recurrence survival (PRS) of the study population after iPDT treatment.

\subsection{Prognostic Factors}

In Table 4, the correlations of prognostic factors with regard to PRS after iPDT are summarized. Univariate analysis showed a significant influence of KPS on PRS $(p=0.019)$. No significant influence of age, MGMT promoter methylation or IDH mutational status, target volume, time to iPDT treatment or any salvage treatment modality on PRS could be found. Time between initial diagnosis and iPDT did not correlate with PRS (Pearson's coefficient, $-0.112, p=0.469$ ) or TTF (Pearson's coefficient, $-0.169, p=0.274$ ). No salvage treatment regimen was associated with an additional survival benefit, neither in the complete study cohort nor in the subgroup of patients with a methylated MGMT promoter sequence. No known prognostic factor was found to correlate with TTF (Supplementary Table S1). FET-PET imaging before treatment was available for 12 patients (median maximum Standardized Uptake Value (SUVmax), 2.95, range, 2.2-8.2) and after treatment for 15 patients (median SUVmax, 2.7, range, 1.5-7.4). Post-therapeutic decrease in SUVmax was associated with longer TTF $(p=0.081)$. 
Table 4. Prognostic factors for PRS after iPDT in uni- and multivariate models; HR—hazard ratio, CI—confidence interval.

\begin{tabular}{ccccccc}
\hline Characteristic & HR & $\begin{array}{c}\text { Univariate } \\
\mathbf{9 5 \%} \text { CI }\end{array}$ & $\boldsymbol{p}$-Value & HR & $\begin{array}{c}\text { Multivariate } \\
\mathbf{9 5 \%} \text { CI }\end{array}$ & $\boldsymbol{p}$-Value \\
\hline Post-recurrence survival (after iPDT) & & & & & & \\
Age at iPDT & 1.006 & $0.981-1.033$ & 0.635 & 1.023 & $0.968-1.080$ \\
KPS at iPDT & 0.936 & $0.886-0.989$ & 0.019 & 1.961 & $0.755-5.092$ & 0.424 \\
MGMT methylation & 0.751 & $0.392-1.438$ & 0.388 & 1.000 & $0.339-2.946$ & 0.167 \\
IDH mutation & 0.878 & $0.405-1.904$ & 0.742 & 1.018 & $0.326-3.178$ \\
Target volume & 1.019 & $0.956-1.086$ & 0.557 & 1.017 & $0.943-1.096$ & 0.976 \\
Time to iPDT & 1.003 & $0.996-1.010$ & 0.392 & 1.003 & $0.992-1.015$ \\
Further chemotherapy & 0.811 & $0.421-1.561$ & 0.530 & 1.030 & $0.443-2.392$ & 0.553 \\
Further radiotherapy & 0.999 & $0.540-1.849$ & 0.999 & 1.005 & $0.317-3.189$ & 0.946 \\
Further surgery & 0.782 & $0.276-2.212$ & 0.643 & 1.303 & $0.258-6.568$ \\
\hline
\end{tabular}

The bold cells are sub-headlines.

\subsection{Intraoperative Spectral Online Monitoring}

Intraoperative transmission and fluorescence data could be evaluated for 18 patients. A total of 300 pre- and postoperative spectra each were analyzed, with one spectrum recorded for each possible fiber pair. The median number of spectra per patient was 24 (range, 12-84). Overall, insufficient postoperative transmission was detected in $21.7 \%$ of the spectra and preoperative fluorescence in $15.8 \%$. Of the 18 patients, $13(72.2 \%)$ showed good postoperative transmission rates between two fibers (of $75 \%$ or more), indicating sufficient illumination over the complete duration of treatment. Ten (55.6\%) also showed PpIX fluorescence over a threshold of $75 \%$. In three $(16.7 \%)$ cases, only preoperative fluorescence was graded as good, but not the postoperative transmission. In all patients, no residual PpIX fluorescence could be detected after the iPDT. Good postoperative transmission and preoperative fluorescence were associated with longer TTF and PRS, although the differences were not highly significant (Table 5).

Table 5. Results of statistical tests of the association of intraoperative spectral online monitoring with time-to-treatment failure (TTF) and post-recurrence survival (PRS), including 95\% confidence intervals (CI).

\begin{tabular}{ccccc}
\hline $\begin{array}{c}\text { Spectral Data } \\
(\boldsymbol{N}=\mathbf{1 8})\end{array}$ & $\begin{array}{c}\text { Median TTF (CI) } \\
\text { (Months) }\end{array}$ & $\boldsymbol{p}$-Value & $\begin{array}{c}\text { Median PRS (CI) } \\
\text { (Months) }\end{array}$ & $p$-Value \\
\hline Transmission $<75 \%$ & $9.63(.978 ; 18.28)$ & & $12.97(12.03 ; 13.92)$ & \\
Transmission $>75 \%$ & $15.73(4.71 ; 24.96))$ & 0.196 & $19.70(4.32 ; 35.08)$ & 0.130 \\
Fluorescence $<75 \%$ & $9.63(4.20 ; 15.06)$ & & $16.57(7.83 ; 25.31)$ & \\
Fluorescence $>75 \%$ & $12.13(3.84 ; 20.42)$ & 0.427 & $17.47(4.20 ; 30.74)$ & 0.326 \\
\hline
\end{tabular}

\section{Discussion}

This study's main findings are: (1) iPDT was technically feasible in all patients; (2) iPDT can be performed with acceptable risk even in highly eloquent tumor localizations; (3) iPDT appears to be associated with favorable treatment effects even in heavily pretreated malignant glioma recurrences; (4) iPDT as part of a salvage treatment concept is associated with considerable long-term survival (PRS $>2$ years) in a-so far-poorly defined subpopulation of malignant glioma patients; (5) treatment success was not associated with any of the known conventional and molecular prognostic factors of malignant gliomas.

Interstitial PDT is a technically demanding form of local treatment that is used for various tumor diseases [44]. Malignant glioma cells are characterized by a selective and effective uptake of systematically administered 5-ALA with subsequent intracellular conversion into the red fluorescent, phototoxic PpIX by exploiting the enzymatic machinery of heme synthesis [45]. As a photosensitizer, PpIX mediates energy transfer from light photons to oxygen molecules to generate reactive oxygen species that lead to oxidation and destruction of membranes, proteins and other vital intracellular structures [46,47]. 
Some of the cell death mechanisms initiated in this manner effectively stimulate the immune response, adding an intriguing systemic effect to this otherwise local treatment modality $[48,49]$.

These characteristics of 5-ALA in combination with the possibility of a spatially precise interstitial illumination by means of a stereotactic frame-based installation of the respective light diffusers make iPDT an attractive tool for local malignant glioma recurrences after standard therapy. This minimally invasive procedure might be of advantage over the technical alternative of a surface PDT, in which an illumination source is introduced directly into the resection cavity at the end of surgery to illuminate any residual tumor tissue. The disadvantage of this method is that the extent of the residual tumor tissue cannot be determined with certainty and the penetration depth of illumination is limited to a few millimeters. However, since a spatially precise illumination of the target tumor volume seems to be fundamental to achieve full treatment effects, the image-guided stereotactic iPDT may be preferred. Moreover, iPDT is not limited to resectable tumors. Only few centers, however, have gained some preliminary clinical experience with iPDT in malignant brain tumors so far (yet unpublished personal communications). To date, just one prospective study has been published which suggested 5-ALA-based iPDT to be safe and feasible for a selected patient population with glioblastoma recurrences [28]. No permanent procedure-related morbidity was seen in the 10 patients treated and select patients survived surprisingly long, possibly thanks to immunological effects known from PDT treatment [50].

This manuscript presents clinical experiences in a large cohort of 44 multimodally pretreated patients who underwent iPDT for small, unifocal and circumscribed malignant glioma recurrences with a maximum extension of $3 \mathrm{~cm}$. This size limitation was based on the maximum number of light fibers per laser and the experimental data, which have shown optimal spacing of light diffusers of about 7-9 $\mathrm{mm}$ for accurate tissue illumination without causing critical thermal effects [28].

Based upon intense interdisciplinary and collaborative efforts, dedicated equipment had been made available so that treatment planning, diffusing fiber insertion and light application were technically feasible in all intended cases. By means of the intraoperative spectral online monitoring technique, transmission of treatment light between fibers and PpIX fluorescence light could be monitored. During most treatments, PpIX fluorescence was characterized as good before starting the illumination and vanished during irradiation, which, at least in cases with good postoperative light transmission grading, indicates substantial consumption of PpIX as expected due to photobleaching of this photosensitizer. The technique of spectral online monitoring seems to be a promising tool to monitor 5ALA administration, PpIX accumulation and fiber placement and potentially to estimate treatment effectiveness. In addition, it was observed that the portion of spectral data indicating good treatment light transmission decreased during treatment. This can be used as an indicator that optical tissue properties change such that the light penetration depth is reduced during iPDT illumination, commonly leading to partial and, in some cases, complete transmission signal loss. The reasons for these changes in the in vivo situation have not yet been investigated and understood in detail. However, this observation is in accordance with a previous study [51], where a reduction of treatment light transmission during iPDT was already reported.

Transient clinical deterioration was recorded in about $40 \%$ of patients and was mainly due to exaggerated edema and/or some hemorrhagic imbibition. The latter observations could not be attributed to direct interference of individual catheter trajectories with intratumoral vascular structures.

Only one patient experienced a grade 3 neurological deterioration persisting for more than six weeks. In this retrospective iPDT study, symptoms usually resolved within six weeks after iPDT even without steroid treatment, which was held back so as not to impede possible immunological effects. The development of perioperative complications was independent of the density of previous tumor treatments, tumor volume and the number 
of laser fibers implanted. This may be due to the limitation to tumors not exceeding $3 \mathrm{~cm}$ in extension suggested by earlier studies [33].

Comparison of these complication rates to those reported after other local treatments is challenging because of differences in patient selection, especially regarding tumor size and potentially eloquent location. In the de novo unselected setting, the current gold standard local treatment, fluorescence-guided resection, has reported adverse events in about $40 \%$ of the cases, with grade 3 or worse aphasia in up to $6 \%$ and hemiparesis in up to $4 \%$ of the treatments [52]. For resection in eloquent location, neurological deterioration in up to $60 \%$ of the treatments has been reported [53]. In the recurrent setting, complication rates for open resection have been suggested to even increase sequentially in each recurrence situation $[54,55]$. As an adjunct or alternative to reresection, re-radiotherapy (with/without bevacizumab) emerged as an increasingly used salvage treatment option after 2011. Notably, toxicity rates of grade III or higher aphasia have been described in between $4 \%$ [56] and 32\% [57] of the treatments. In summary, in an often multimodally pretreated and symptomatic patient population, any local treatment is associated with an increased risk of at least transient morbidity.

The observed median PRS of 13.0 months is in the upper range of the median PRS originated by other treatment modalities, ranging mostly between seven and nine months [17]. In the DIRECTOR study where first glioblastoma recurrences were treated with different temozolomide dose regimens, PRS ranged between 7.9 months for MGMT-unmethylated and 12.5 months for MGMT-methylated tumors [58]. In that cohort, complete resection of contrast enhancement was associated with a more favorable PRS of 12.9 months, compared to incomplete resection (PRS, 6.5 months) and no resection (PRS, 9.8 months), indicating, like the present study, a benefit of local treatment if possible [10].

In the present iPDT cohort, no influence of molecular markers such as MGMT and IDH on response to iPDT with or without adjuvant therapy including temozolomide can be observed. Different numbers and types of pretreatments and a heterogeneous patient population may explain the lack of an observable effect or a still too low total number of cases, as other studies also did not uniformly observe a prognostic effect of MGMT promoter methylation or lack thereof in recurrent situations [58,59]. Due to different treatment groups in different studies, a direct meaningful comparison of outcome data is rather difficult. Interestingly, though, more than $20 \%$ of patients in the iPDT series survived more than two years after malignant glioma recurrence irrespective of time to PDT and later salvage treatments and even with MGMT-unmethylated primary glioblastomas. This high percentage of long-term survivors warrants further investigation. As shown, common prognostic factors in malignant glioma patients did not differ between long-term and short-term survivors in this cohort, based on a threshold PRS of two years. Possibly, immunological factors may play a role, as has been suggested in experimental settings [60,61]. One of the key factors stimulating the immune response may be the heat shock protein HSP-70 as it was shown that sublethal 5-ALA PDT upregulated HSP-70 by up to 50-fold in glioma cells [49]. The upregulation of HSP-70 and the fact that 5-ALA PDT on glioma spheroids attracted and matured coincubated dendritic cells was experimentally confirmed [62]. The cell death mechanisms glioblastoma cells in a patient treated with iPDT undergo are expected to be very heterogeneous, as both light distribution and photosensitizer distribution are not homogenous. Therefore, parts of the tumor may undergo direct necrosis, others-apoptotic cell death and some cells in the periphery may survive. However, the plethora of cell death mechanisms initiated may be advantageous for an efficient stimulation of immune response with presentation of damage-associated molecular patterns, production of inflammatory cytokines such as interleukin 6 and attraction and maturation of dendritic cells, altogether leading to recruitment of effector T cells as reviewed in [63]. These authors suggested a combined therapeutic approach of PDT with immune checkpoint blockade. Further research, especially into immunological processes surrounding glioblastoma treatment, is required to gain more detailed and specific knowledge to benefit most from iPDT. 
In addition, standard MRI images after iPDT showed loss of contrast and FET enhancement and a change in the diffusion restriction precisely confined to the treatment volume. The interpretation of such findings with regard to mechanisms and clinical relevance will be addressed in future studies. Importantly, data interpretation in this study is not hampered by immunologically induced imaging effects as tumor recurrence was histologically verified in all non-palliative cases.

\section{Conclusions}

Interstitial PDT of gliomas remains a challenging procedure due to limited light penetration depth in brain tissue, a complex planning and implantation procedure and potential risk of clinical deterioration especially after treatment in eloquent areas. Nevertheless, in experienced hands, iPDT may be a promising treatment option in a high-risk patient population combining acceptable, mostly transient morbidity with the possibility of long-term survival. It does not critically interfere with but may rather complement other treatment options in the recurrent disease such as re-radiotherapy and/or salvage chemotherapy regimens. These data strongly support further investigation in a controlled prospective setting.

Supplementary Materials: The following are available online at https:/ /www.mdpi.com/article/10 .3390 / cancers13081767/s1, Figure S1: Survival curves. (a) Overall survival of the intention to treat population after initial tumor diagnosis; (b) time-to-treatment failure (TTF) of the intention to treat population after iPDT treatment; (c) post-recurrence survival (PRS) of the intention to treat population after iPDT treatment; Table S1: Prognostic factors for TTF after iPDT in uni- and multivariate models HR-Hazard ratio, CI—confidence interval.

Author Contributions: Conceptualization, S.L., R.S., H.S., A.R. and N.T.; methodology, S.L., M.S. and M.A.; validation, C.S., J.W. and H.S.; formal analysis, S.L.; investigation, M.S., S.L.; resources, R.E., R.F.; data curation, M.S., S.L.; writing — original draft preparation, S.L., M.S. and M.A.; writingreview and editing, C.S., J.W., S.S., C.H., R.F., M.N., R.E., H.S., R.S., J.-C.T., A.R. and N.T.; visualization, S.L.; supervision, A.R., N.T. and R.S.; project administration A.R., N.T. and R.S.; funding acquisition, A.R., N.T. and R.S. All authors have read and agreed to the published version of the manuscript.

Funding: We thank the German Research Foundation (DFG) for financial support of the research training group (RTG) GRK2274.

Institutional Review Board Statement: The study was conducted according to the guidelines of the Declaration of Helsinki and approved by the Ethics Committee of Ludwig Maximilian University, Munich, Germany (reference number 19-650).

Informed Consent Statement: Informed consent was obtained from all subjects involved in the study.

Data Availability Statement: No new data were created or analyzed in this study. Data sharing is not applicable to this article.

Acknowledgments: We gratefully acknowledge Christoph Barth and Wolfgang Beyer for technical assistance.

Conflicts of Interest: The authors declare no conflict of interest. The funders had no role in the design of the study; in the collection, analyses, or interpretation of data; in the writing of the manuscript, or in the decision to publish the results.

\section{References}

1. Stupp, R.; Taillibert, S.; Kanner, A.A.; Kesari, S.; Steinberg, D.M.; Toms, S.A.; Taylor, L.P.; Lieberman, F.; Silvani, A.; Fink, K.L.; et al. Maintenance Therapy with Tumor-Treating Fields Plus Temozolomide vs Temozolomide Alone for Glioblastoma: A Randomized Clinical Trial. JAMA 2015, 314, 2535-2543. [CrossRef]

2. Stupp, R.; Taillibert, S.; Kanner, A.; Read, W.; Steinberg, D.M.; Lhermitte, B.; Toms, S.; Idbaih, A.; Ahluwalia, M.S.; Fink, K.; et al. Effect of Tumor-Treating Fields Plus Maintenance Temozolomide vs Maintenance Temozolomide Alone on Survival in Patients with Glioblastoma: A Randomized Clinical Trial. JAMA 2017, 318, 2306-2316. [CrossRef]

3. Nam, J.Y.; Groot, J.F.D. Treatment of Glioblastoma. J. Oncol. Pract. 2017, 13, 629-638. [CrossRef] [PubMed] 
4. Brada, M.; Hoang-Xuan, K.; Rampling, R.; Dietrich, P.Y.; Dirix, L.Y.; Macdonald, D.; Heimans, J.J.; Zonnenberg, B.A.; BravoMarques, J.M.; Henriksson, R.; et al. Multicenter phase II trial of temozolomide in patients with glioblastoma multiforme at first relapse. Ann. Oncol. 2001, 12, 259-266. [CrossRef] [PubMed]

5. Lombardi, G.; De Salvo, G.L.; Brandes, A.A.; Eoli, M.; Rudà, R.; Faedi, M.; Lolli, I.; Pace, A.; Daniele, B.; Pasqualetti, F.; et al. Regorafenib compared with lomustine in patients with relapsed glioblastoma (REGOMA): A multicentre, open-label, randomised, controlled, phase 2 trial. Lancet Oncol. 2019, 20, 110-119. [CrossRef]

6. Stupp, R.; Wong, E.T.; Kanner, A.A.; Steinberg, D.; Engelhard, H.; Heidecke, V.; Kirson, E.D.; Taillibert, S.; Liebermann, F.; Dbaly, V.; et al. NovoTTF-100A versus physician's choice chemotherapy in recurrent glioblastoma: A randomised phase III trial of a novel treatment modality. Eur. J. Cancer (Oxf. Engl. 1990) 2012, 48, 2192-2202. [CrossRef]

7. Weller, M.; Le Rhun, E. How did lomustine become standard of care in recurrent glioblastoma? Cancer Treat. Rev. 2020, 87, 102029. [CrossRef]

8. Desjardins, A.; Gromeier, M.; Herndon, J.E., 2nd; Beaubier, N.; Bolognesi, D.P.; Friedman, A.H.; Friedman, H.S.; McSherry, F.; Muscat, A.M.; Nair, S.; et al. Recurrent Glioblastoma Treated with Recombinant Poliovirus. N. Engl. J. Med. 2018, 379, 150-161. [CrossRef] [PubMed]

9. Puduvalli, V.K.; Wu, J.; Yuan, Y.; Armstrong, T.S.; Vera, E.; Wu, J.; Xu, J.; Giglio, P.; Colman, H.; Walbert, T.; et al. A Bayesian Adaptive Randomized Phase II Multicenter Trial of Bevacizumab with or without Vorinostat in Adults with Recurrent Glioblastoma. Neuro-Oncology 2020, 1505-1515. [CrossRef] [PubMed]

10. Suchorska, B.; Weller, M.; Tabatabai, G.; Senft, C.; Hau, P.; Sabel, M.C.; Herrlinger, U.; Ketter, R.; Schlegel, U.; Marosi, C.; et al. Complete resection of contrast-enhancing tumor volume is associated with improved survival in recurrent glioblastoma-results from the DIRECTOR trial. Neuro-Oncology 2016, 18, 549-556. [CrossRef]

11. Chiocca, E.A.; Yu, J.S.; Lukas, R.V.; Solomon, I.H.; Ligon, K.L.; Nakashima, H.; Triggs, D.A.; Reardon, D.A.; Wen, P.; Stopa, B.M.; et al. Regulatable interleukin-12 gene therapy in patients with recurrent high-grade glioma: Results of a phase 1 trial. Sci. Transl. Med. 2019, 11. [CrossRef]

12. Cloughesy, T.F.; Petrecca, K.; Walbert, T.; Butowski, N.; Salacz, M.; Perry, J.; Damek, D.; Bota, D.; Bettegowda, C.; Zhu, J.J.; et al. Effect of Vocimagene Amiretrorepvec in Combination With Flucytosine vs Standard of Care on Survival Following Tumor Resection in Patients With Recurrent High-Grade Glioma: A Randomized Clinical Trial. JAMA Oncol. 2020, 6, 1939-1946. [CrossRef] [PubMed]

13. Stummer, W.; Reulen, H.J.; Meinel, T.; Pichlmeier, U.; Schumacher, W.; Tonn, J.C.; Rohde, V.; Oppel, F.; Turowski, B.; Woiciechowsky, C.; et al. Extent of resection and survival in glioblastoma multiforme: Identification of and adjustment for bias. Neurosurgery 2008, 62, 564-576. [CrossRef] [PubMed]

14. Lu, V.M.; Jue, T.R.; McDonald, K.L.; Rovin, R.A. The Survival Effect of Repeat Surgery at Glioblastoma Recurrence and its Trend: A Systematic Review and Meta-Analysis. World Neurosurg. 2018, 115, 453-459. [CrossRef] [PubMed]

15. Wann, A.; Tully, P.A.; Barnes, E.H.; Lwin, Z.; Jeffree, R.; Drummond, K.J.; Gan, H.; Khasraw, M. Outcomes after second surgery for recurrent glioblastoma: A retrospective case-control study. J. Neuro-Oncol. 2018, 137, 409-415. [CrossRef]

16. Wick, W.; Gorlia, T.; Bendszus, M.; Taphoorn, M.; Sahm, F.; Harting, I.; Brandes, A.A.; Taal, W.; Domont, J.; Idbaih, A.; et al. Lomustine and Bevacizumab in Progressive Glioblastoma. N. Engl. J. Med. 2017, 377, 1954-1963. [CrossRef]

17. Seystahl, K.; Wick, W.; Weller, M. Therapeutic options in recurrent glioblastoma-An update. Crit. Rev. Oncol./Hematol. 2016, 99, 389-408. [CrossRef]

18. Rosenthal, M.A.; Gruber, M.L.; Glass, J.; Nirenberg, A.; Finlay, J.; Hochster, H.; Muggia, F.M. Phase II Study of Combination Taxol and Estramustine Phosphate in the Treatment of Recurrent Glioblastoma Multiforme. J. Neuro-Oncol. 2000, 47, 59-63. [CrossRef]

19. Oudard, S.; Carpentier, A.; Banu, E.; Fauchon, F.; Celerier, D.; Poupon, M.F.; Dutrillaux, B.; Andrieu, J.M.; Delattre, J.Y. Phase II study of lonidamine and diazepam in the treatment of recurrent glioblastoma multiforme. J. Neuro-Oncol. 2003, 63, 81-86. [CrossRef] [PubMed]

20. Puduvalli, V.K.; Yung, W.K.; Hess, K.R.; Kuhn, J.G.; Groves, M.D.; Levin, V.A.; Zwiebel, J.; Chang, S.M.; Cloughesy, T.F.; Junck, L.; et al. Phase II study of fenretinide (NSC 374551) in adults with recurrent malignant gliomas: A North American Brain Tumor Consortium study. J. Clin. Oncol. Off. J. Am. Soc. Clin. Oncol. 2004, 22, 4282-4289. [CrossRef]

21. Robe, P.A.; Martin, D.H.; Nguyen-Khac, M.T.; Artesi, M.; Deprez, M.; Albert, A.; Vanbelle, S.; Califice, S.; Bredel, M.; Bours, V. Early termination of ISRCTN45828668, a phase $1 / 2$ prospective, randomized study of sulfasalazine for the treatment of progressing malignant gliomas in adults. BMC Cancer 2009, 9, 1-8. [CrossRef] [PubMed]

22. Rich, J.N.; Reardon, D.A.; Peery, T.; Dowell, J.M.; Quinn, J.A.; Penne, K.L.; Wikstrand, C.J.; Van Duyn, L.B.; Dancey, J.E.; McLendon, R.E.; et al. Phase II trial of gefitinib in recurrent glioblastoma. J. Clin. Oncol. Off. J. Am. Soc. Clin. Oncol. 2004, 22, 133-142. [CrossRef] [PubMed]

23. Sathornsumetee, S.; Desjardins, A.; Vredenburgh, J.J.; McLendon, R.E.; Marcello, J.; Herndon, J.E.; Mathe, A.; Hamilton, M.; Rich, J.N.; Norfleet, J.A.; et al. Phase II trial of bevacizumab and erlotinib in patients with recurrent malignant glioma. Neuro-Oncology 2010, 12, 1300-1310. [CrossRef]

24. Wick, W.; Puduvalli, V.K.; Chamberlain, M.C.; van den Bent, M.J.; Carpentier, A.F.; Cher, L.M.; Mason, W.; Weller, M.; Hong, S.; Musib, L.; et al. Phase III study of enzastaurin compared with lomustine in the treatment of recurrent intracranial glioblastoma. J. Clin. Oncol. Off. J. Am. Soc. Clin. Oncol. 2010, 28, 1168-1174. [CrossRef] [PubMed] 
25. Filley, A.C.; Henriquez, M.; Dey, M. Recurrent glioma clinical trial, CheckMate-143: The game is not over yet. Oncotarget 2017, 8, 91779-91794. [CrossRef] [PubMed]

26. Lim, M.; Xia, Y.; Bettegowda, C.; Weller, M. Current state of immunotherapy for glioblastoma. Nat. Rev. Clin. Oncol. 2018, 15, 422-442. [CrossRef]

27. Stupp, R.; Brada, M.; van den Bent, M.J.; Tonn, J.-C.; Pentheroudakis, G. High-grade glioma: ESMO Clinical Practice Guidelines for diagnosis, treatment and follow-upt. Ann. Oncol. 2014, 25, iii93-iii101. [CrossRef]

28. Beck, T.J.; Kreth, F.W.; Beyer, W.; Mehrkens, J.H.; Obermeier, A.; Stepp, H.; Stummer, W.; Baumgartner, R. Interstitial photodynamic therapy of nonresectable malignant glioma recurrences using 5-aminolevulinic acid induced protoporphyrin IX. Lasers Surg. Med. 2007, 39, 386-393. [CrossRef]

29. Stummer, W.; Pichlmeier, U.; Meinel, T.; Wiestler, O.D.; Zanella, F.; Reulen, H.J. Fluorescence-guided surgery with 5-aminolevulinic acid for resection of malignant glioma: A randomised controlled multicentre phase III trial. Lancet. Oncol. 2006, 7, $392-401$. [CrossRef]

30. Schucht, P.; Beck, J.; Abu-Isa, J.; Andereggen, L.; Murek, M.; Seidel, K.; Stieglitz, L.; Raabe, A. Gross total resection rates in contemporary glioblastoma surgery: Results of an institutional protocol combining 5-aminolevulinic acid intraoperative fluorescence imaging and brain mapping. Neurosurgery 2012, 71, 927-935. [CrossRef]

31. Stylli, S.S.; Kaye, A.H.; MacGregor, L.; Howes, M.; Rajendra, P. Photodynamic therapy of high grade glioma-long term survival. J. Clin. Neurosci. Off. J. Neurosurg. Soc. Australas. 2005, 12, 389-398. [CrossRef]

32. Dupont, C.; Vermandel, M.; Leroy, H.-A.; Quidet, M.; Lecomte, F.; Delhem, N.; Mordon, S.; Reyns, N. INtraoperative photoDYnamic Therapy for GliOblastomas (INDYGO): Study protocol for a phase I clinical trial. Neurosurgery 2018. [CrossRef] [PubMed]

33. Johansson, A.; Faber, F.; Kniebühler, G.; Stepp, H.; Sroka, R.; Egensperger, R.; Beyer, W.; Kreth, F.-W. Protoporphyrin IX Fluorescence and Photobleaching During Interstitial Photodynamic Therapy of Malignant Gliomas for Early Treatment Prognosis. Lasers Surg. Med. 2013, 45, 225-234. [CrossRef] [PubMed]

34. Stummer, W.; Beck, T.; Beyer, W.; Mehrkens, J.H.; Obermeier, A.; Etminan, N.; Stepp, H.; Tonn, J.C.; Baumgartner, R.; Herms, J.; et al. Long-sustaining response in a patient with non-resectable, distant recurrence of glioblastoma multiforme treated by interstitial photodynamic therapy using 5-ALA: Case report. J. Neuro-Oncol. 2008, 87, 103-109. [CrossRef] [PubMed]

35. Macdonald, D.R.; Cascino, T.L.; Schold, S.C., Jr.; Cairncross, J.G. Response criteria for phase II studies of supratentorial malignant glioma. J. Clin. Oncol. Off. J. Am. Soc. Clin. Oncol. 1990, 8, 1277-1280. [CrossRef] [PubMed]

36. Wen, P.Y.; Macdonald, D.R.; Reardon, D.A.; Cloughesy, T.F.; Sorensen, A.G.; Galanis, E.; Degroot, J.; Wick, W.; Gilbert, M.R.; Lassman, A.B.; et al. Updated response assessment criteria for high-grade gliomas: Response assessment in neuro-oncology working group. J. Clin. Oncol. Off. J. Am. Soc. Clin. Oncol. 2010, 28, 1963-1972. [CrossRef]

37. Eigenbrod, S.; Trabold, R.; Brucker, D.; Eros, C.; Egensperger, R.; La Fougere, C.; Gobel, W.; Ruhm, A.; Kretzschmar, H.A.; Tonn, J.C.; et al. Molecular stereotactic biopsy technique improves diagnostic accuracy and enables personalized treatment strategies in glioma patients. Acta Neurochir. 2014, 156, 1427-1440. [CrossRef]

38. Louis, D.N.; Ohgaki, H.; Wiestler, O.D.; Cavenee, W.K.; Burger, P.C.; Jouvet, A.; Scheithauer, B.W.; Kleihues, P. The 2007 WHO Classification of Tumours of the Central Nervous System. Acta Neuropathol. 2007, 114, 97-109. [CrossRef]

39. Louis, D.N.; Perry, A.; Reifenberger, G.; von Deimling, A.; Figarella-Branger, D.; Cavenee, W.K.; Ohgaki, H.; Wiestler, O.D.; Kleihues, P.; Ellison, D.W. The 2016 World Health Organization Classification of Tumors of the Central Nervous System: A summary. Acta Neuropathol. 2016, 131, 803-820. [CrossRef]

40. Rühm, A.; Stepp, H.; Beyer, W.; Hennig, G.; Pongratz, T.; Sroka, R.; Schnell, O.; Tonn, J.-C.; Kreth, F.-W. 5-ALA based photodynamic management of glioblastoma. In Proceedings of the SPIE, San Francisco, CA, USA, 24 March 2014.

41. National Institutes of Health Common Terminology Criteria for Adverse Events (CTCAE); National Cancer Institute: Bethesda, MD, USA, 2017.

42. Rachinger, W.; Goetz, C.; Popperl, G.; Gildehaus, F.J.; Kreth, F.W.; Holtmannspotter, M.; Herms, J.; Koch, W.; Tatsch, K.; Tonn, J.C. Positron emission tomography with O- $\left(2-\left[{ }^{18} \mathrm{~F}\right]\right.$ fluoroethyl)-l-tyrosine versus magnetic resonance imaging in the diagnosis of recurrent gliomas. Neurosurgery 2005, 57, 505-511. [CrossRef]

43. Mehrkens, J.H.; Popperl, G.; Rachinger, W.; Herms, J.; Seelos, K.; Tatsch, K.; Tonn, J.C.; Kreth, F.W. The positive predictive value of O-(2-[ $\left.{ }^{18} \mathrm{~F}\right]$ fluoroethyl)-L-tyrosine (FET) PET in the diagnosis of a glioma recurrence after multimodal treatment. J. Neuro-Oncol. 2008, 88, 27-35. [CrossRef] [PubMed]

44. Shafirstein, G.; Bellnier, D.; Oakley, E.; Hamilton, S.; Potasek, M.; Beeson, K.; Parilov, E. Interstitial Photodynamic Therapy-A Focused Review. Cancers 2017, 9, 12. [CrossRef] [PubMed]

45. Collaud, S.; Juzeniene, A.; Moan, J.; Lange, N. On the selectivity of 5-aminolevulinic acid-induced protoporphyrin IX formation. Curr. Med. Chem. Anti-Cancer Agents 2004, 4, 301-316. [CrossRef]

46. Agostinis, P.; Berg, K.; Cengel, K.A.; Foster, T.H.; Girotti, A.W.; Gollnick, S.O.; Hahn, S.M.; Hamblin, M.R.; Juzeniene, A.; Kessel, D.; et al. Photodynamic therapy of cancer: An update. CA A Cancer J. Clin. 2011, 61, 250-281. [CrossRef]

47. Stepp, H.; Stummer, W. 5-ALA in the management of malignant glioma. Lasers Surg. Med. 2018, 50, 399-419. [CrossRef] [PubMed]

48. Beltrán Hernández, I.; Yu, Y.; Ossendorp, F.; Korbelik, M.; Oliveira, S. Preclinical and Clinical Evidence of Immune Responses Triggered in Oncologic Photodynamic Therapy: Clinical Recommendations. J. Clin. Med. 2020, 9, 333. [CrossRef] 
49. Kammerer, R.; Buchner, A.; Palluch, P.; Pongratz, T.; Oboukhovskij, K.; Beyer, W.; Johansson, A.; Stepp, H.; Baumgartner, R.; Zimmermann, W. Induction of immune mediators in glioma and prostate cancer cells by non-lethal photodynamic therapy. PLoS ONE 2011, 6, e21834. [CrossRef] [PubMed]

50. Castano, A.P.; Mroz, P.; Hamblin, M.R. Photodynamic therapy and anti-tumour immunity. Nat. Rev. Cancer 2006, 6, 535-545. [CrossRef]

51. Heckl, C.; Aumiller, M.; Rühm, A.; Sroka, R.; Stepp, H. Fluorescence and Treatment Light Monitoring for Interstitial Photodynamic Therapy. Photochem. Photobiol. 2020, 96, 388-396. [CrossRef]

52. Stummer, W.; Tonn, J.C.; Mehdorn, H.M.; Nestler, U.; Franz, K.; Goetz, C.; Bink, A.; Pichlmeier, U. Counterbalancing risks and gains from extended resections in malignant glioma surgery: A supplemental analysis from the randomized 5-aminolevulinic acid glioma resection study. Clinical article. J. Neurosurg. 2011, 114, 613-623. [CrossRef]

53. Magill, S.T.; Han, S.J.; Li, J.; Berger, M.S. Resection of primary motor cortex tumors: Feasibility and surgical outcomes. J. Neurosurg. 2018, 129, 961-972. [CrossRef] [PubMed]

54. Chang, S.M.; Parney, I.F.; McDermott, M.; Barker, F.G., 2nd; Schmidt, M.H.; Huang, W.; Laws, E.R., Jr.; Lillehei, K.O.; Bernstein, M.; Brem, H.; et al. Perioperative complications and neurological outcomes of first and second craniotomies among patients enrolled in the Glioma Outcome Project. J. Neurosurg. 2003, 98, 1175-1181. [CrossRef] [PubMed]

55. Hoover, J.M.; Nwojo, M.; Puffer, R.; Mandrekar, J.; Meyer, F.B.; Parney, I.F. Surgical outcomes in recurrent glioma: Clinical article. J. Neurosurg. 2013, 118, 1224-1231. [CrossRef]

56. Flieger, M.; Ganswindt, U.; Schwarz, S.B.; Kreth, F.W.; Tonn, J.C.; la Fougere, C.; Ertl, L.; Linn, J.; Herrlinger, U.; Belka, C.; et al. Re-irradiation and bevacizumab in recurrent high-grade glioma: An effective treatment option. J. Neuro-Oncol. 2014, 117, 337-345. [CrossRef] [PubMed]

57. Lee, J.; Ahn, S.S.; Chang, J.H.; Suh, C.O. Hypofractionated Re-irradiation after Maximal Surgical Resection for Recurrent Glioblastoma: Therapeutic Adequacy and Its Prognosticators of Survival. Yonsei Med. J. 2018, 59, 194-201. [CrossRef] [PubMed]

58. Weller, M.; Tabatabai, G.; Kästner, B.; Felsberg, J.; Steinbach, J.P.; Wick, A.; Schnell, O.; Hau, P.; Herrlinger, U.; Sabel, M.C.; et al. MGMT Promoter Methylation Is a Strong Prognostic Biomarker for Benefit from Dose-Intensified Temozolomide Rechallenge in Progressive Glioblastoma: The DIRECTOR Trial. Clin. Cancer Res. An Off. J. Am. Assoc. Cancer Res. 2015, 21, 2057-2064. [CrossRef]

59. Wick, W.; Meisner, C.; Hentschel, B.; Platten, M.; Schilling, A.; Wiestler, B.; Sabel, M.C.; Koeppen, S.; Ketter, R.; Weiler, M.; et al. Prognostic or predictive value of MGMT promoter methylation in gliomas depends on IDH1 mutation. Neurology 2013, 81, 1515-1522. [CrossRef] [PubMed]

60. Li, F.; Cheng, Y.; Lu, J.; Hu, R.; Wan, Q.; Feng, H. Photodynamic therapy boosts anti-glioma immunity in mice: A dependence on the activities of T cells and complement C3. J. Cell. Biochem. 2011, 112, 3035-3043. [CrossRef]

61. Hübner, M.; Strauss, G.; Effinger, D.; Pohla, H.; Kreth, F.-W.; Kreth, S. IMPS-15PDT-TREATED GBM CELLS INCREASE EFFECTOR FUNCTIONS OF HUMAN CD8+ T-CELLS. Neuro-Oncology 2015, 17, v116. [CrossRef]

62. Etminan, N.; Peters, C.; Lakbir, D.; Bünemann, E.; Börger, V.; Sabel, M.C.; Hänggi, D.; Steiger, H.J.; Stummer, W.; Sorg, R.V. Heat-shock protein 70-dependent dendritic cell activation by 5 -aminolevulinic acid-mediated photodynamic treatment of human glioblastoma spheroids in vitro. Br. J. Cancer 2011, 105, 961-969. [CrossRef]

63. Cramer, G.M.; Moon, E.K.; Cengel, K.A.; Busch, T.M. Photodynamic Therapy and Immune Checkpoint Blockade(†). Photochem. Photobiol. 2020, 96, 954-961. [CrossRef] [PubMed] 